\title{
MOLECULAR DOCKING STUDIES FOR THE COMPARATIVE ANALYSIS OF DIFFERENT BIOMOLECULES TO TARGET HYPOXIA INDUCIBLE FACTOR-1 $\alpha$
}

\author{
NIRAJ KUMAR JHA ${ }^{1}$, PRAVIR KUMAR ${ }^{1 \dagger}$ \\ ${ }^{1}$ Molecular Neuroscience and Functional Genomics Laboratory, Delhi Technological University (Formerly DCE), Delhi 110042 \\ Email: pravirkumar@dce.edu
}

Received: 28 Apr 2017, Revised and Accepted: 14 Jun 2017

\begin{abstract}
Objective: Hypoxia plays a significant role in governing many vital signalling molecules in the central nervous system (CNS). Hypoxic exposure has also been depicted as a stimulus for oxidative stress, increase in lipid peroxidation, DNA damage, blood-brain dysfunction, impaired calcium $\left(\mathrm{Ca}^{2+}\right)$ homoeostasis and agglomeration of oxidized biomolecules in neurons, which act as a novel signature in diverse neurodegenerative and oncogenic processes. On the contrary, the presence of abnormally impaired expression of HIF-1 $\alpha$ under hypoxic insult could serve as an indication of the existence of tumors and neuronal dysfunction as well. For instance, under hypoxic stress, amyloid- $\beta$ protein precursor (A $\beta$ PP) cleavage is triggered due to the higher expression of HIF-1 $\alpha$ and thus leads to synaptic loss. The objective of this research is to perform comparative studies of biomolecules in regulating HIF-1 $\alpha$ activity based on in silico approaches that could establish a potential therapeutic window for the treatment of different abnormalities associated with impaired HIF- $1 \alpha$.
\end{abstract}

Methods: We employed various in silico methods such as drug-likeness parameters namely Lipinski filter analysis, Muscle tool, SWISS-MODEL, active site prediction, Auto Dock 4.2.1 and LigPlot1.4.5for molecular docking studies.

Results: 3D structure of HIF-1 $\alpha$ was generated and Ramachandran plot obtained for quality assessment. RAMPAGE displayed $99.5 \%$ of residues in the most favoured regions. $0 \%$ residues in additionally allowed and $0.5 \%$ disallowed regions of the HIF- $1 \alpha$ protein. Further, initial screenings of the molecules were done based on Lipinski's rule of five. Cast P server used to predict the ligand binding site suggests that this protein can be utilised as a potential drug target. Finally, we have found Naringenin to be most effective amongst three biomolecules in modulating HIF-1 $\alpha$ based on minimum inhibition constant, Ki and highest negative free energy of binding with the maximum interacting surface area during docking studies.

Conclusion: The present study outlines the novel potential of Biomolecules in regulating HIF-1 $\alpha$ activity for the treatment of different abnormalities associated with impaired HIF-1 $\alpha$.

Keywords: Hypoxia-inducible factor- $1 \alpha(\mathrm{HIF}-1 \alpha)$, Biomolecules, Active site prediction, Molecular docking

(C) 2017 The Authors. Published by Innovare Academic Sciences Pvt Ltd. This is an open access article under the CC BY license (http://creativecommons.org/licenses/by/4.0/) DOI: http://dx.doi.org/10.22159/ijap.2017v9i4.19505

\section{INTRODUCTION}

Hypoxia plays a decisive role in controlling many important signalling molecules in the central nervous system (CNS) [1]. At the higher altitude, low barometric pressure causes accelerated expression of HIF gene. Hypoxia inhibits prolyl hydroxylation of HIF-1 $\alpha$ leading to aggregation of a functional heterodimeric transcription factor (both HIF1 $\alpha$ and HIF1 $\beta$ subunits) [2]. Hypoxia-inducible factor-1 (HIF-1) is a key transcriptional factor which is amenable for cellular adaption to low oxygen tension. It is a heterodimer comprising of an oxygenregulated $\alpha$-subunit and a constitutively expressed $\beta$-subunit that regulates a series of genes associated with iron metabolism, angiogenesis, cell proliferation/survival and glucose metabolism [3].

The activity of HIF-1 is regulated by post-translational modifications on different amino acid residues of its subunits, mainly the $\alpha$-subunit. It has been reported that under hypoxic insult, the activity of HIF-1 and expression of its associated downstream genes, such as vascular endothelial growth factor (VEGF) and erythropoietin (EPO) are altered in a range of neurodegenerative diseases (NDDs) including Alzheimer's disease (AD), Parkinson's disease (PD) and Amyotrophic lateral sclerosis (ALS) [4]. It has also been reported that hypoxia causes reduced synaptic transmission associated with neuronal death by causing neuronal dysfunction [5]. Thus, elucidation of pathophysiological mechanisms caused due to hypoxic insults on the cerebral nervous system (CNS); their therapeutic regulation awaits much importance. Further, experimental and clinical evidence has revealed that regulating the expression of HIF-1 $\alpha$ might improve the cellular and tissue damage in the NDDs. This regulatory role on the expression of HIF-1 $\alpha$ can be accompanied by employing different biomolecules.

Naringenin (5, 7, 4-trihydroxyflavanone, NGEN) is a flavanone, mainly found in the citrus fruits and tomato. It is known to be act as a multi-functional agent. For example, it acts as a powerful anti- oxidant, anti-depressant, anti-inflammatory and neuroprotective compound [6]. Similarly, Sesamol is the major constituent of sesame seed oil (Sesamum indicum) possessing powerful antioxidant property. Further, it acts as chemoprotective, anti-inflammatory, neuroprotective, hepatoprotective, and anti-aging biomolecule [7]. Another, well-known biomolecules, Quercetin (2-(3,4dihydroxyphenyl)-3,5, 7-tryhydroxy-4H-chromen-4-one, QUR) possess anti-oxidant, anti-inflammatory and in some cases anticancerous activities [8]. These biomolecules are having neuroprotective properties as proposed to be potent therapeutic agents in many diseases, including cognitive impairment associated with neuronal damage. Although, regulating the function of HIF-1 $\alpha$ are crucial to be investigated that have protective effects on the pathological ambiances resulting from hypoxic insults in the brain. Therefore, in this research report, we have done in silico based comparative study of three different biomolecules (Naringenin, Sesamol and Quercetin) in order to regulate the impaired functions of HIF- $1 \alpha$. These molecules have been identified and selected for this study through Lipinski rule of five. However, several in vitro studies have explored its neuroprotective activities in different neuronal cell cultures and animal models $[9,10]$. But a comparative study of these biomolecules on the expression of HIF-1 $\alpha$ by using in silico tools has not been explored so far, which we are going to explore in this article. In the present study, we reported the Phylogenetic and Physico-chemical properties of HIF- $1 \alpha$ gene, since we have selected this gene as a target protein for docking study. Further, Homology modelling visualization and quality assessment of 3D-structure of HIF- $1 \alpha$ has been addressed. Additionally, active site prediction and ligand optimisation for both the biomolecules and protein has been done in order to perform molecular docking. Further, we found and docking study revealed that all three compounds were interacting at the reported active and binding site. Finally, in this result the most effective compound was found to be Naringenin as showing 
minimum Inhibition Constant, Ki and highest negative free energy of binding with maximum interacting surface area suggesting that Naringenin could be effective as HIF-1 $\alpha$ regulators and therefore act as potential therapeutic molecules for treating patients suffering from hypoxic insults.

\section{MATERIALS AND METHODS}

Retrieval of hypoxia inducible factor protein and its function recognition

The amino acid sequence of hypoxia inducible factor protein HIF- $1 \alpha$ with accession number Q16665.1 of Homo sapiens was retrieved from NCBI database and was used for homology search using Basic Local Alignment Search Tool (BLAST). Protein functional elucidation was done using Interproscan server (https://www.ebi.ac.uk/ interpro/search/sequence-search).

\section{Phylogenetic relationship and physicochemical properties}

For multiple sequence analysis Muscle tool (http://www.ebi.ac.uk/ Tools/msa/muscle/) was used and a phylogenetic tree was constructed using Muscle tool based on NJ (Neighbor-joining) plot without distance correction. ProtParam (http://web.expasy.org/ protparam/) was used to predict physicochemical properties. The parameters computed by ProtParam included the molecular weight, theoretical PI, aliphatic index and grand average of hydropathicity (GRAVY).

\section{Homology modelling, visualisation and quality assessment of} 3D-structure of hypoxia-inducible factor

Homology modeling was used to determine the 3D-structure of HIF$1 \alpha$ isoforms. A BLASTP search with default parameters was performed against the Brookhaven Protein Data Bank (PDB) to find suitable templates for homology modelling. Template with PDB ID: 4H6J was retrieved for HIF-1 1 protein from PDB. The Protein Structure Prediction Server SWISS-MODEL (http://swissmodel.expasy.org/) was used for homology model construction. Once the 3D-structure of proteins was generated, structural evaluation and stereochemical analysis were performed using RAMPAGE (http://www.mordred. bioc.cam.ac.uk/ rapper/rampage.php). Errat server was used to find the accuracy of the structure and visualisation of determined structures was performed using UCSF Chimera.

\section{Active site prediction}

Castp Server (http://www.sts.bioe.uic.edu/castp/) was used to predict the active sites of the protein. Castp could also be used to measure area, the circumference of mouth openings of each binding site insolvent and molecular accessible surface. PDB file of protein was uploaded in the server and it showed the ligand binding sites present in protein and the site with maximum surface area and maximum surface volume was selected and all the amino acid residues involved in binding with ligands were retrieved.

\section{Ligand optimization}

Reported ligand molecules along with their physical and chemical properties were retrieved from Pub chem compound database (http://www.pubchem.ncbi.nlm.nih.gov/). Pubchem is a composite database that is backed up by three primary databases, i.e. PC substance, PC compound, and PC BioAssay. Pubchem provides biological activity and chemical information of small molecules. PC substance contains information about the substances; PC compound contains information about chemical compounds, and PCBio assay provides information about Bioassays. Four compounds (Naringenin, Quercetin, and Sesamol) were selected. SDF files of Ligands were converted in PDB file with the help of Open Babel tool that could be used for docking study. Visualization of Molecular Structure of compounds was done using Pymol.

\section{Lipinski filter analysis of screened drugs}

An online tool Lipinski Filter (http://www.scfbio-iitd.res.in/ software/drug design/lipinski.jsp) was used to retrieve the information about drug-likeness properties of Biomolecules with the help of Lipinski rule of five. Lipinski rule helps to differentiate drug and non-drug like properties of molecules. It is used to identify the possibility of success or failure due to drug-likeness for molecules fulfilling with two or more of the following rules: (a) Molecular Mass should be less than 500 Dalton, (b) High Lipophilicity (expressed as $\log$ P less than 5), (c) Less than 5 hydrogen bond donors, (d) Less than 10 hydrogen bond acceptors and (e) Molar refractivity should be between $40-130$.

\section{Preparation of protein and ligand molecules}

Preparation of protein involves the addition of polar hydrogen atoms, neutralisation of charge and removal of any miscellaneous structures from the protein molecule by Autodock 4.2.1 whereas ligand preparation involves the neutralization of charge.

\section{Molecular docking studies}

Prepared and optimised structures of ligands and protein were ultimately used for molecular docking using Autodock 4.2.1 for predicting the possible protein-ligand interactions and the results that include the understanding of the association that involves $\mathrm{H}$ bonding and hydrophobic interactions were analyzed using LigPlot1.4.5, a program to generate schematic diagrams of proteinligand interactions.

\section{RESULTS}

\section{Retrieval of hypoxia inducible factor protein and its functional elucidation}

Based on functional domain sequence of well-characterized gene/protein, a homology search was done using BLAST. We have successfully hunted 5 isoforms (table 1 ) of protein HIF- $1 \alpha$ on the basis of families and domains identified from Interproscan results. Interproscan study revealed that all homologues proteins for HIF-1 $\alpha$ were belonging to Hypoxia-inducible factor, $\alpha$-subunit family (IPR021537), Hypoxia-inducible factor- $1 \alpha$ family (IPR001321), Myctype, basic helix-loop-helix domain (IPR011598), PAS domain (IPR000014), PAS fold (IPR013767), PAS fold 3 (IPR013655), HIF$1 \alpha$, transactivation domain, C-terminal (IPR014887) and a repeat of PAC motif (IPR001610)respectively (fig. 1).

Table 1: Hunted HIF-1 $\alpha$ related proteins

\begin{tabular}{|c|c|c|c|c|c|}
\hline S. No. & Accession No. & Protein & Score & Identity & E Value \\
\hline 1 & NP_001521.1 & hypoxia-inducible factor 1 -alpha isoform 1 & 1721 & $100 \%$ & 0 \\
\hline 2 & AKI70676.1 & HIF1A & 1719 & $99 \%$ & 0 \\
\hline 3 & AAC68568.1 & hypoxia-inducible factor 1 alpha subunit & 1718 & $99 \%$ & 0 \\
\hline 4 & NP_001230013.1 & hypoxia-inducible factor 1 -alpha isoform 3 & 1696 & $99 \%$ & 0 \\
\hline 5 & Q9XTA5.1 & Hypoxia-inducible factor 1-alpha & 1624 & $95 \%$ & 0 \\
\hline
\end{tabular}

\section{Phylogenetic relationship and physicochemical properties}

For multiple sequence analysis, Muscle tool was used and found that amino acid residues were conserved in most of the isoforms of the protein HIF-1 $\alpha$ (fig. 2a). A phylogenetic study of HIF-1 $\alpha$ hunted proteins revealed that HIF- $1 \alpha$ and HIF1A were in the same cluster as they share the same homology and HIF-1 $\alpha$ isoform 1 was in another cluster while HIF-1 $\alpha$ isoform 3 and HIF- $1 \alpha$ subunit were differed from others (fig. $2 b$ ). ProtParam showed that Mol. wt. of HIF-1 $\alpha$ was 92670.4 Daltons. An isoelectric point for HIF-1 $1 \alpha$ was 5.17 which indicates that protein was negatively charged. The GRAVY index of- 0.573 for HIF-1 $\alpha$ is indicative of hydrophilic and soluble protein (table 2). 


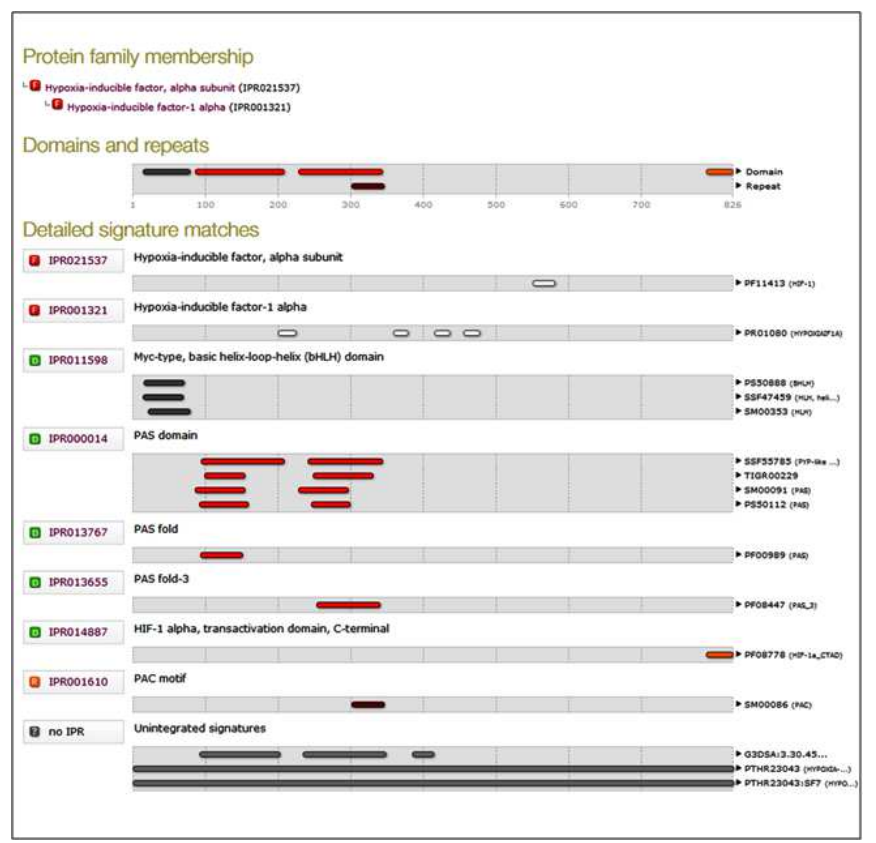

Fig. 1: Interproscan result for HIF-1- $\alpha$ family and their domain identification

\begin{tabular}{|c|c|}
\hline aIF-1-alphal & IERPUERSRDQUUSRP SIESEV \\
\hline aIr-1-alpha__sotorn_31 & 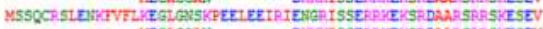 \\
\hline AlF-1-alpha_-180:0In_-11 & 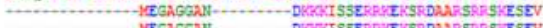 \\
\hline HIFIAI & 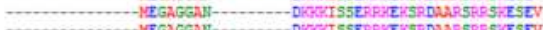 \\
\hline HIF-1-alpha_gubunit! & 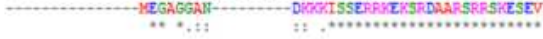 \\
\hline HIF-1-alphal & 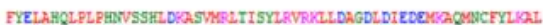 \\
\hline HIF-1-alpho__isotorn_31 & 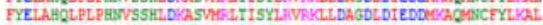 \\
\hline art-1-alpha_isoform_1i & 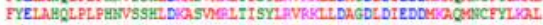 \\
\hline GIт1ล & 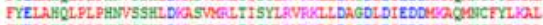 \\
\hline AIF-1-alphe_gubunit| & 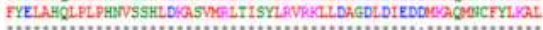 \\
\hline aIf-1-alghal & 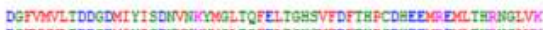 \\
\hline aIY-1-o1pha_190:om_3i & 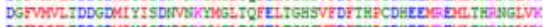 \\
\hline HIF-1-alpha_isotorn_11 & 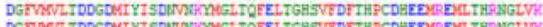 \\
\hline & 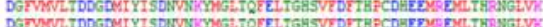 \\
\hline gIIF-1-alpha_gubunit| & 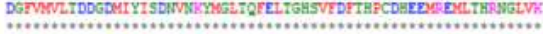 \\
\hline HIF-1-alphal & 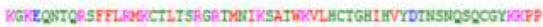 \\
\hline HIY-1-alpha__9otorn_31 & 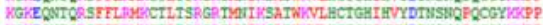 \\
\hline HIF-1-aIpha__19oform_11 & 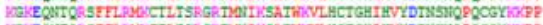 \\
\hline aIFIAI & 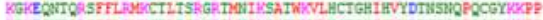 \\
\hline MrF-1-alpha_gubunit! & 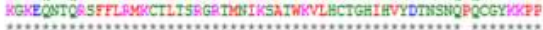 \\
\hline & \\
\hline $\begin{array}{ll}\text { HIF-1-alphal } \\
\text { HIF }\end{array}$ & 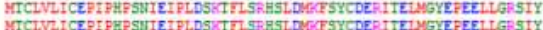 \\
\hline 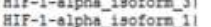 & 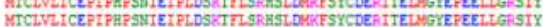 \\
\hline HIMAI & 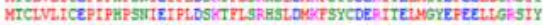 \\
\hline AlF-1-alpha_subunit| & 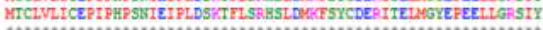 \\
\hline & \\
\hline MIr-1-aiphal & 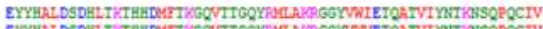 \\
\hline 1.pha_19oform_31 & 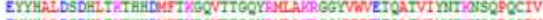 \\
\hline 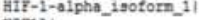 & 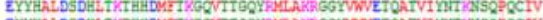 \\
\hline HIF1a| & 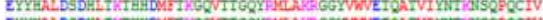 \\
\hline HIf-1-alphan_subunit! & 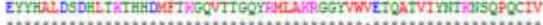 \\
\hline
\end{tabular}

(a)

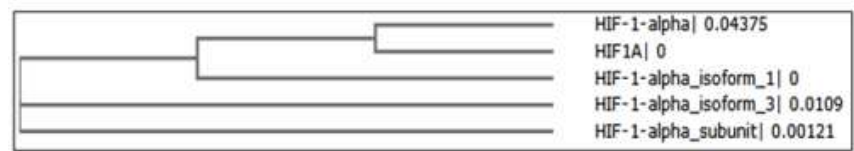

(b)

Fig. 2: (a) Multiple sequence alignment and (b) phylogenetic analysis of all HIF-1 $\alpha$ isoforms

Table 2: Physico-chemical properties of HIF-1 $\alpha$

\begin{tabular}{ll}
\hline Properties & HIF-1 $\boldsymbol{\alpha}$ \\
\hline Molecular Formula & $\mathrm{C}_{4027} \mathrm{H}_{6410} \mathrm{~N}_{1108} \mathrm{O}_{1309} \mathrm{~S}_{43}$ \\
Molecular Weight (Daltons) & 92670.4 \\
Theoretical PI & 5.17 \\
Aliphatic Index & 74.96 \\
Grand Average of Hydropathicity (GRAVY) & -0.573 \\
\hline
\end{tabular}




\section{Homology modelling}

Prediction of 3D-structure of proteins provides us precise functional information of how proteins interact and localize in their stable conformation. Homology modelling is a most common structure prediction method in structural genomics and proteomics. The best matching template was selected for the target protein on the basis of sequence homology using PDB Advance Blast. The template is experimentally determined 3D- structure of protein that shares sequence similarity with the target sequence. Template showed a sequence identity of $99.07 \%$ for HIF-1 $\alpha$ isoforms. 3D-structure of HIF-1 $\alpha$ was generated using Swiss-Model Server. The Z-score is indicative of overall model quality and is used to check whether the input structure is within the range of scores typically found for native proteins of similar size. Z-score of the template and query model was obtained by SWISS-MODEL. Z-score for HIF- $1 \alpha$ was-0.81 suggesting a good structure (table 3).

Table 3: Swiss model server result showing template structure used in homology modelling, sequence identity and quality score of the model generated

\begin{tabular}{lllll}
\hline Gene name & Modelled residue range & Based on template & Sequence identity & QMEAN Z-score \\
\hline HIF- $\alpha$ & $139-811$ & $4 \mathrm{H} 6 \mathrm{~J}$ & $99.07 \%$ & -0.81 \\
\hline
\end{tabular}

\section{D-structure visualization and quality assessment}

3D-structure of HIF-1 $\alpha$ transcription factor was generated and visualized using UCSF Chimera (fig. 3a). Even though there were no steric clashes in the structure generated, it was assessed for geometric and energy aspects. Ramachandran plot was used to check the reliability of predicted 3D-structure of hypoxia inducible factor protein HIF-1 $\alpha$. RAMPAGE checks the stereochemical quality of a protein structure by analysing residue-by-residue geometry and overall structural geometry. Ramachandran plot was obtained for HIF-1 1 for quality assessment. RAMPAGE displayed $99.5 \%$ of residues in the most favoured regions, $0.5 \%$ residues in additionally allowed and no residues in disallowed regions in HIF-1 $\alpha$ Protein (fig. $3 b)$. Errat server was used to determine the accuracy of the model. The result of Errat showed $95.694 \%$ accurate structure for HIF-1 $\alpha$ protein.

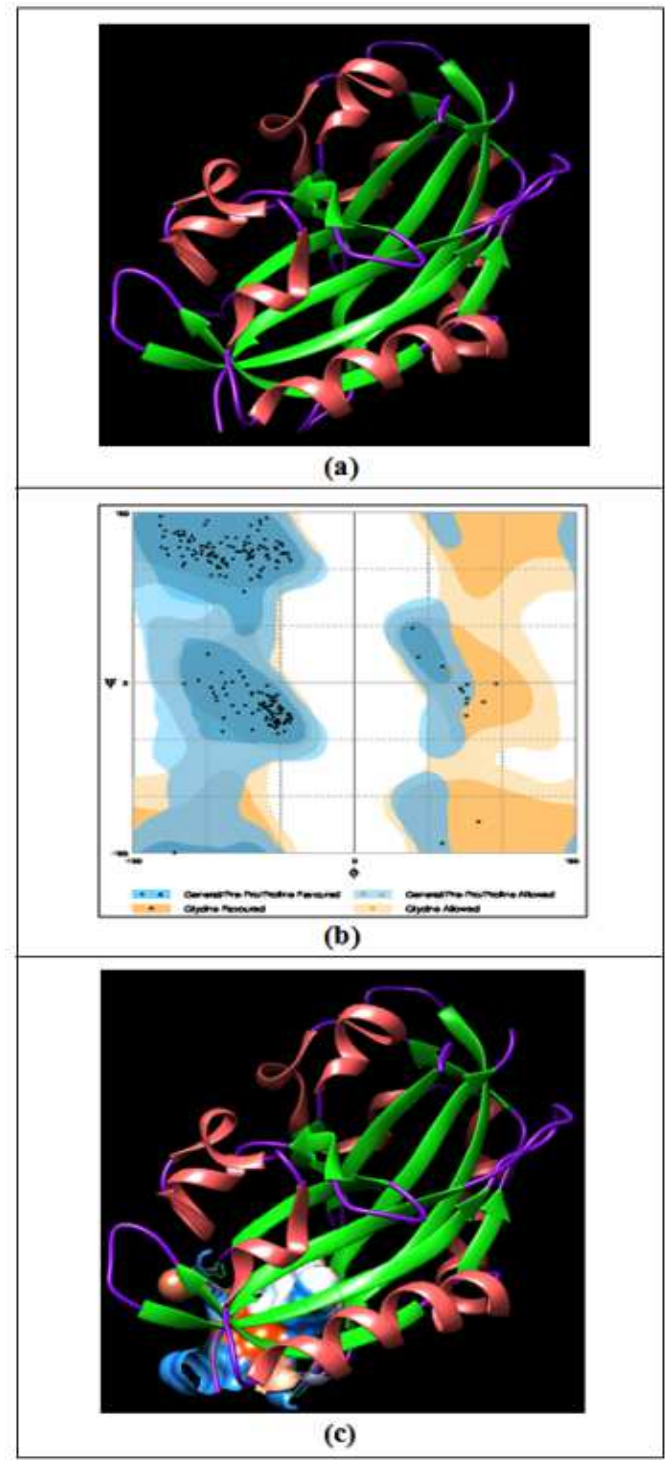

Fig. 3: (a) 3D-Structure, (b) Ramachandran Plot and (c) Active site of generated HIF-1 $\alpha$ model 


\section{Active site prediction}

CastP server was used to predict the ligand binding sites in the generated 3D-structure of HIF-1 $\alpha$. This server calculates the possible active sites from the 3D atomic coordinates of the protein (fig. 3c).
Among the twenty-nine binding sites obtained from CastP for HIF$1 \alpha$, site 29 was highly conserved within the active site of the protein. The Predicted site 29 consisted 415.4 Cubic angstroms site volume out of the 1661.1 Cubic Angstroms of protein volume. The residues in site twenty-nine are shown in (table 6).

Table 4: Physico-chemical properties of natural compounds used for docking study

\begin{tabular}{|c|c|c|c|}
\hline Characteristics & Naringenin & Quercetin & Sesamol \\
\hline Molecular weight & $272.25278 \mathrm{~g} / \mathrm{mol}$ & $302.2357 \mathrm{~g} / \mathrm{mol}$ & $138.12074 \mathrm{~g} / \mathrm{mol}$ \\
\hline Molecular Formula & $\mathrm{C}_{15} \mathrm{H}_{12} \mathrm{O}_{5}$ & $\mathrm{C}_{15} \mathrm{H}_{10} \mathrm{O}_{7}$ & $\mathrm{C}_{7} \mathrm{H}_{6} \mathrm{O}_{3}$ \\
\hline IUPAC Name & $\begin{array}{l}\text { 5,7-dihydroxy-2-(4-hydroxyphenyl)-2,3- } \\
\text { dihydrochromen-4-one }\end{array}$ & $\begin{array}{l}\text { 2-(3,4-dihydroxyphenyl)-3,5,7- } \\
\text { trihydroxychromen-4-one }\end{array}$ & 1,3-benzodioxol-5-ol \\
\hline Rotatable Bond Count & 1 & 1 & 0 \\
\hline $\begin{array}{l}\text { Topological Polar } \\
\text { Surface Area }\end{array}$ & $87 A^{2}$ & $127 \mathrm{~A}^{2}$ & $38.7 \mathrm{~A}^{2}$ \\
\hline Heavy Atom Count & 20 & 22 & 10 \\
\hline Complexity & 363 & 488 & 126 \\
\hline
\end{tabular}

Further, the screening of ligand molecules was done on the basis of Lipinski's rule of five. Lipinski filter analysis revealed that all the compounds selected possessed drug likeness and can be used for docking purposes (fig. 4).

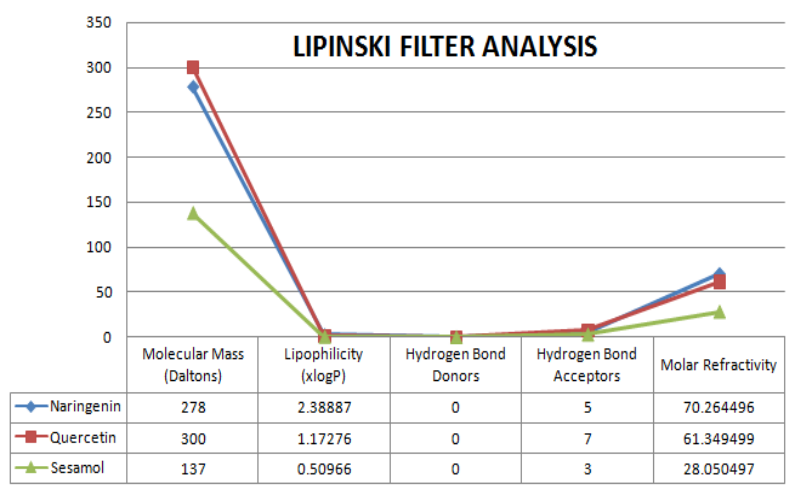

Fig. 4: Differentiation of drugs on the basis of lipinski rule of five by lipinski filter

\section{Docking calculation of compounds with HIF-1A}

\section{HIF-1 $\alpha$ interaction with Naringenin}

Free energy of binding with Naringeninwas- $8.48 \mathrm{kcal} / \mathrm{mol}$ and Est. Inhibition Constant, Ki was found to be $605.40 \mathrm{nM}$. Intermolecular
Energy was found to be- $9.68 \mathrm{kcal} / \mathrm{mol}$. VdW+Hbond+desolv Energy and Electrostatic Energy was $-9.62 \mathrm{kcal} / \mathrm{mol}$ and $-0.06 \mathrm{kcal} / \mathrm{mol}$. Total Internal Energy and Torsional Free Energy was found to be 9.70 $\mathrm{kcal} / \mathrm{mol}$ and $1.19 \mathrm{kcal} / \mathrm{mol}$.

\section{HIF-1 $\alpha$ interaction with Quercetin}

Free energy of binding with Quercetinwas-8.22 kcal/mol and Est. Inhibition Constant, Ki was found to be $945.18 \mathrm{nM}$. Intermolecular Energy was found to be- $10.01 \mathrm{kcal} / \mathrm{mol}$. VdW+Hbond+desolv Energy and Electrostatic Energy was $-9.81 \mathrm{kcal} / \mathrm{mol}$ and $-0.20 \mathrm{kcal} / \mathrm{mol}$. Total Internal Energy and Torsional Free Energy was found to be 9.51 $\mathrm{kcal} / \mathrm{mol}$ and $1.79 \mathrm{kcal} / \mathrm{mol}$.

\section{HIF-1 $\alpha$ interaction with Sesamol}

Free energy of binding with Sesamol was $-5.13 \mathrm{kcal} / \mathrm{mol}$ and Est. Inhibition Constant, Ki was found to be $174.23 \mu \mathrm{M}$. Intermolecular Energy was found to be $-5.43 \mathrm{kcal} / \mathrm{mol}$. VdW+Hbond+desolv Energy and Electrostatic Energy was-5.34 kcal/mol and-0.08 $\mathrm{kcal} / \mathrm{mol}$. Total Internal Energy and Torsional Free Energy was found to be $0.32 \mathrm{kcal} / \mathrm{mol}$ and $0.30 \mathrm{kcal} / \mathrm{mol}$. Docked energy estimation of HIF- $1 \alpha$ is shown in table 5 and interaction of HIF- $1 \alpha$ with ligands is shown in (fig. 5).

Binding site of HIF-1 $\alpha$ with selected compounds along with its reported Inhibitory active site

Binding site residues of HIF- $1 \alpha$ interacting with Naringenin, Quercetin and Sesamol were found to be the same as the residues involved in their respective catalytic sites. Interacting residues of HIF- $1 \alpha$ with Naringenin, Quercetin and Sesamol along with their identified catalytic sites have been shown in (table 6) and their 2D and 3D pattern of interaction is presented in (fig. 6).

Table 5: Docking calculation of compounds with HIF-1 $\alpha$

\begin{tabular}{|c|c|c|c|c|c|c|c|}
\hline $\begin{array}{l}\text { Compoun } \\
\text { d name }\end{array}$ & $\begin{array}{l}\text { Est. free } \\
\text { energy of } \\
\text { binding }\end{array}$ & $\begin{array}{l}\text { Est. } \\
\text { binding } \\
\text { constant }\end{array}$ & $\begin{array}{l}\text { Est. } \\
\text { intermolecular } \\
\text { energy }\end{array}$ & $\begin{array}{l}\text { vdW+Hbond+desol } \\
\text { v energy }\end{array}$ & $\begin{array}{l}\text { Electrostatic } \\
\text { energy }\end{array}$ & $\begin{array}{l}\text { Est. internal } \\
\text { energy }\end{array}$ & $\begin{array}{l}\text { Torsional free } \\
\text { energy }\end{array}$ \\
\hline Naringenin & $\begin{array}{l}-8.48 \\
(\mathrm{kcal} / \mathrm{mol})\end{array}$ & $\begin{array}{l}605.40 \\
\mathrm{nM}\end{array}$ & $-9.68(\mathrm{kcal} / \mathrm{mol})$ & $-9.62(\mathrm{kcal} / \mathrm{mol})$ & $\begin{array}{l}-0.06 \\
(\mathrm{kcal} / \mathrm{mol})\end{array}$ & $\begin{array}{l}+9.70 \\
(\mathrm{kcal} / \mathrm{mol})\end{array}$ & $\begin{array}{l}+1.19 \\
(\mathrm{kcal} / \mathrm{mol})\end{array}$ \\
\hline Quercetin & $\begin{array}{l}-8.22 \\
(\mathrm{kcal} / \mathrm{mol})\end{array}$ & $\begin{array}{l}945.18 \\
\mathrm{nM}\end{array}$ & - $10.01(\mathrm{kcal} / \mathrm{mol})$ & $-9.81(\mathrm{kcal} / \mathrm{mol})$ & $\begin{array}{l}-0.20 \\
(\mathrm{kcal} / \mathrm{mol})\end{array}$ & $\begin{array}{l}+9.51 \\
(\mathrm{kcal} / \mathrm{mol})\end{array}$ & $\begin{array}{l}+1.79 \\
(\mathrm{kcal} / \mathrm{mol})\end{array}$ \\
\hline Sesamol & $\begin{array}{l}-5.13 \\
(\mathrm{kcal} / \mathrm{mol})\end{array}$ & $\begin{array}{l}174.23 \\
\mu \mathrm{M}\end{array}$ & $-5.43(\mathrm{kcal} / \mathrm{mol})$ & $-5.34(\mathrm{kcal} / \mathrm{mol})$ & $\begin{array}{l}-0.08 \\
(\mathrm{kcal} / \mathrm{mol})\end{array}$ & $\begin{array}{l}+0.32 \\
(\mathrm{kcal} / \mathrm{mol})\end{array}$ & $\begin{array}{l}+0.30 \\
(\mathrm{kcal} / \mathrm{mol})\end{array}$ \\
\hline
\end{tabular}




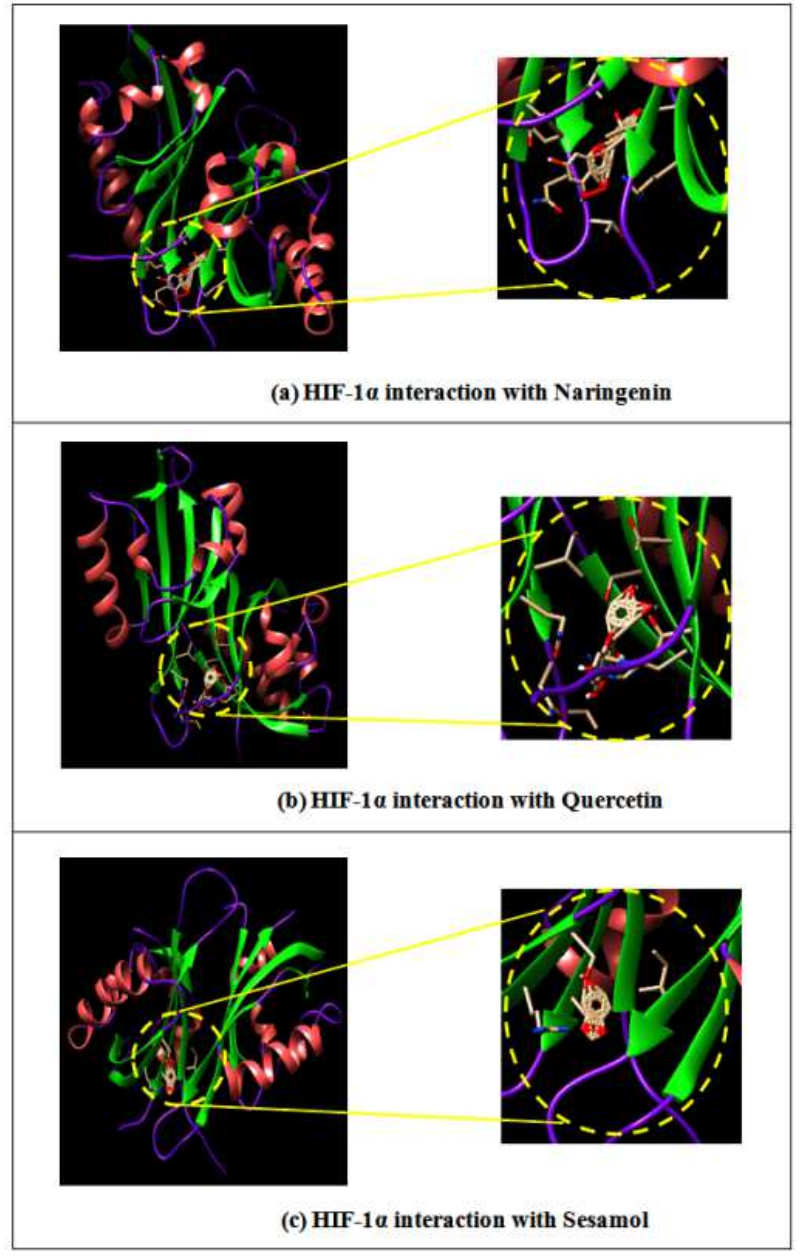

Fig. 5: Binding of HIF-1 $\alpha$ with selected compounds

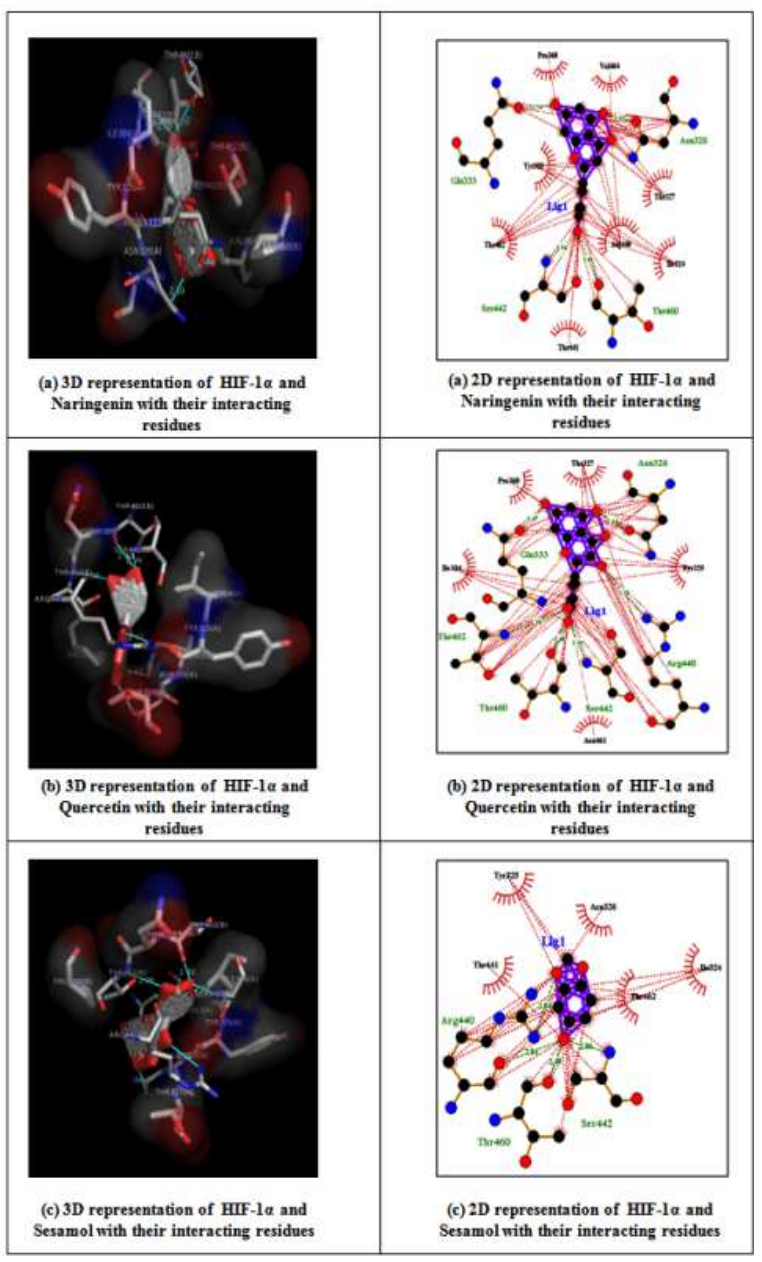

Fig. 6: 3D-and 2D-representation of HIF-1 $\alpha$ and ligand interactio

Table 6: HIF-1 $\alpha$ known inhibitory site and selected compounds interacting residues

\begin{tabular}{|c|c|}
\hline Compounds & Interacting residues \\
\hline Reported Active & $\mathrm{ILE}^{324}, \mathrm{TYR}^{325}, \mathrm{ASN}^{326}, \mathrm{THR}^{327}, \mathrm{LYS}^{328}, \mathrm{GLN}^{333}$ and CYS 334 of chain A and CYS ${ }^{358}, \mathrm{GLN}^{359}, \mathrm{PRO}^{360}, \mathrm{ARG}^{362}, \mathrm{MET}^{426}, \mathrm{ARG}^{440}, \mathrm{THR}^{441}$, \\
\hline Site & $\mathrm{SER}^{442}, \mathrm{THR}^{460}, \mathrm{ASN}^{461}, \mathrm{THR}^{462}, \mathrm{ASN}^{463}, \mathrm{VAL}^{464}$ and $\mathrm{LYS}^{465}$ of chain B. \\
\hline Naringenin & $\begin{array}{l}\mathrm{ILE}^{324}, \mathrm{ASN}^{326}, \mathrm{TYR}^{325}, \mathrm{THR}^{327} \text { and } \mathrm{GLN}^{333} \text { residues of chain A and PRO }{ }^{360}, \mathrm{ARG}^{440}, \mathrm{THR}^{441}, \mathrm{SER}^{442}, \mathrm{THR}^{460}, \mathrm{THR}^{462} \text { and } \mathrm{VAL}^{464} \\
\text { residues of chain } \mathrm{B} \text {. }\end{array}$ \\
\hline Quercetin & $\begin{array}{l}\mathrm{ILE}^{324}, \mathrm{TYR}^{325}, \mathrm{ASN}^{326}, \mathrm{THR}^{327} \text { and } \mathrm{GLN}^{333} \text { residues of chain A and } \mathrm{PRO}^{360}, \mathrm{ARG}^{440}, \mathrm{SER}^{442}, \mathrm{THR}^{460}, \mathrm{ASN}^{461} \text { and } \mathrm{THR}^{462} \text { residues of } \\
\text { chain B. }\end{array}$ \\
\hline Sesamol & ILE $^{324}$, TYR $^{325}$ and $\mathrm{ASN}^{326}$ residues of chain A and $\mathrm{ARG}^{440}, \mathrm{THR}^{441} \mathrm{SER}^{442}$, THR ${ }^{460}$ and $\mathrm{THR}^{462}$ residues of chain B. \\
\hline
\end{tabular}

\section{DISCUSSION}

Further, recent therapeutics advancement in hypoxia-mediated aberrations reveals the promising role of natural compounds as potent neuroprotective agents. By this in the silico investigation, we have successfully hunted 5 unique hits using BLAST [11] based on functional domain sequence and optimized the full-length genes of HIF- $1 \alpha$ on the basis of families and domains identified from Interproscan results. These isoforms belong to Hypoxia-inducible factor, alpha subunit family (IPR021537), Hypoxia-inducible factor-1 alpha family (IPR001321), Myc-type, basic helix-loop-helix domain (IPR011598), PAS domain (IPR000014), PAS fold (IPR013767), PAS fold 3 (IPR013655), HIF-1 alpha, transactivation domain, C-terminal (IPR014887) and a repeat of PAC motif (IPR001610) and catalyse functions based on its activity to regulate the transcriptional activity in areas of vascularization and angiogenesis, energy metabolism, cell survival and tumour invasion. Further, the Phylogenetic study of HIF-1 $\alpha$ revealed that hypoxia-inducible factor $1 \alpha$ and HIF1A were in same cluster as they share the same homology and hypoxiainducible factor $1 \alpha$ isoform 1 was in another cluster while Hypoxia- inducible factor 1-alpha isoform 3 and hypoxia-inducible factor $1 \alpha$ subunit were differed from others [12]. ProtParam results showed that isoelectric point was 5.17 which indicates that protein was negatively charged thus it could be better for docking analysis. TheGRAVYindexis- 0.573 for HIF- $1 \alpha$ is indicative of hydrophilic and soluble protein. Template showed $99.07 \%$ sequence identity for HIF$1 \alpha$ protein which is another important property for proper ligand interaction. 3D-structure of HIF-1 $\alpha$ was generated by using SWISS MODEL Server [13] and visualized using UCSF Chimera [14]. Z score for HIF-1 $\alpha$ was 0.81 respectively suggesting that input structure is within the range of scores typically found for native proteins of similar size. RAMPAGE displayed $99.5 \%$ of residues in the most favoured regions, $0.5 \%$ residues in additionally allowed and no residues in disallowed regions in HIF-1 $\alpha$ Protein, showing that stereochemical quality of protein structure is good and which is important for proper docking. The result of Errat showed 95.694\% accurate structure for HIF-1 $\alpha$ protein. Among the twenty-nine binding sites obtained from CastP Server for HIF-1 $\alpha$, site 29 was highly conserved within all the binding sites of HIF-1 $\alpha$ protein [15]. Further, active site prediction was performed since it is useful to 
determine potential sites for ligand binding in molecular docking. Three compounds (Naringenin, Quercetin and Sesamol) obtained from different medicinal plants were selected for molecular docking study at in silico level. Lipinski Filter Analysis of all the compounds revealed that these compounds could act like a drug and have druglike property as these compounds meet the criteria of Lipinski Rule of five [16]. Docking study revealed that all four compounds are interacting at the reported active and binding site [17, 18]. Inhibition Constant, Ki of Naringenin, Quercetin and Sesamol for HIF$1 \alpha$ was found to be $605.40 \mathrm{nM}, 945.18 \mathrm{nM}$ and $174.23 \mu \mathrm{M}$ respectively suggesting that all the selected compounds are effective as HIF- $1 \alpha$ inhibitors. Investigation of active and binding sites within HIF- $1 \alpha$ protein and gives a better idea for a valuable drug target site and drug interaction with the highest affinity. In this result, the most effective compound was found to be Naringenin as showing minimum Inhibition Constant, Ki and highest negative free energy of binding with maximum interacting surface area [19-22].

\section{CONCLUSION}

In the light of the above analysis, we found that modulating the HIF$1 \alpha$ activity could be helpful for curing many disease progressions. Since, altered expression of this important transcription factor directs many abnormalities, including neuronal dysfunction and cancers. Further, in silico studies revealed that biomolecules might have a role in the inhibition of HIF- $1 \alpha$ and in the prevention of hypoxiamediated cellular dysfunction. All the biomolecules which have been selected for docking study are having drug-like property and may act as potential biomolecules for inhibiting or targeting the altered expression of HIF-1 $\alpha$. The in silico molecular docking study results revealed that all the biomolecules are having minimum binding energy and have good affinity toward the active pocket, thus, they may be supposed as good inhibitor of HIF- $1 \alpha$. Inhibition Constant, Ki of Naringenin, Quercetin and Sesamol for HIF-1 $\alpha$ was found to be $605.40 \mathrm{nM}$, $945.18 \mathrm{nM}$ and $174.23 \mu \mathrm{M}$ respectively, advocating that all the selected compounds are effective as HIF-1 $\alpha$ inhibitors. Additionally, investigation of active and binding sites within HIF- $1 \alpha$ protein gives a better idea for a valuable drug target site and drug interaction with the highest affinity. Finally, in this result the most effective compound was found to be Naringenin as showing minimum inhibition constant, Ki and highest negative free energy of binding with the maximum interacting surface area. Thus, the role of natural compound Naringenin with HIF-1 $\alpha$ provides a novel remedial approach among all three biomolecules based on docking studies and provide a potential curative biomarker for the treatment of patients suffering from hypoxic injuries.

\section{ACKNOWLEDGEMENT}

The authors would like to thank the senior management of DTU for their encouragement and support. The authors would also like to thank Technical Education Quality Improvement Programme-II (TEQIP-II) for providing Fellowship to NKJ.

\section{CONFLICTS OF INTERESTS}

The authors declare no conflict of interest.

\section{REFERENCES}

1. Li L, Welser JV, Dore-Duffy P. In the hypoxic central nervous system, endothelial cell proliferation is followed by astrocyte activation, proliferation, and increased expression of the alpha 6 beta 4 integrin and dystroglycan. Glia 2010;58:1157-67.

2. Keith B, Johnson RS, Simon MC. HIF1 $\alpha$ and HIF2 $\alpha$ : sibling rivalry in hypoxic tumour growth and progression. Nat Rev Cancer 2011;12:9-22.

3. Correia SC, Carvalho C, Cardoso S. Defective HIF signaling pathway and brain response to hypoxia in neurodegenerative diseases: not an "iffy" question. Curr Pharm Des 2013;19:6809-22.
4. Ziello JE, Jovin IS, Huang Y. Hypoxia-inducible factor (HIF)-1 regulatory pathway and its potential for therapeutic intervention in malignancy and ischemia. Yale J Biol Med 2007;80:51-60.

5. Mukandala G, Tynan R, Lanigan S. The effects of hypoxia and inflammation on synaptic signaling in the CNS. Brain Sci 2016;6:E6.

6. Oh YS. Bioactive compounds and their neuroprotective effects in diabetic complications. Nutrients 2016;8:E472.

7. Mahendra Kumar C, Singh SA. Bioactive lignans from sesame (Sesamumindicum L.): evaluation of their antioxidant and antibacterial effects for food applications. J Food SciTechnol 2015;52:2934-41.

8. Zhang L, Lokeshwar BL. Medicinal properties of the Jamaican pepper plant Pimentadioica and Allspice. Curr Drug Targets 2012;13:1900-6.

9. Sonia Angeline M, Sarkar A, Anand K. Sesamol and naringenin reverse the effect of rotenone-induced PD rat model. Neuroscience 2013;254:379-94.

10. Sarkar A, Angeline MS, Anand K. Naringenin and quercetin reverse the effect of hypobaric hypoxia and elicit a neuroprotective response in the murine model. Brain Res 2012;1481:59-70.

11. Altschul SF, Gish W, Miller W. Basic local alignment search tool. J Mol Biol 1990;215:403-10.

12. Edgar RC. MUSCLE: a multiple sequence alignment method with reduced time and space complexity. BMC Bioinformatics 2004;5:113.

13. Arnold K, Bordoli L, Kopp J. The SWISS-MODEL workspace: a web-based environment for protein structure homology modeling. Bioinformatics 2006;22:195-201.

14. Yang Z, Lasker K, Schneidman-Duhovny D. UCSF Chimera, MODELLER, and IMP: an integrated modeling system. J Struct Biol 2012;179:269-78.

15. Dundas J, Ouyang Z, Tseng J. CASTp: computed atlas of surface topography of proteins with structural and topographical mapping of functionally annotated residues. Nucleic Acids Res 2006;34:W116-118.

16. Lipinski CA. Lead-and drug-like compounds: the rule-of-five revolution. Drug Discovery Today Technol 2004;1:337-41.

17. Pradeepkiran JA, Kumar KK, Kumar YN. Modeling, molecular dynamics and docking assessment of transcription factor rho: a potential drug target in Brucellamelitensis 16M. Drug Des Dev Ther 2015;9:1897-912.

18. Park H, Lee J, Lee S. Critical assessment of the automated AutoDock as a new docking tool for virtual screening. Proteins 2006;65:549-54.

19. Pranjaligupta, Nishant Rai, Pankaj Gautam. Anticancer drugs as potential inhibitors of acrab-tolc of multidrug-resistant Escherichia coli: an in silico molecular modeling and docking study. Asian J Pharm Clin Res. 2015;8:351-8.

20. Sri dharani R, Ranjitha R, Sripathi R, Ali muhammad KS, Ravi S. Docking studies in target proteins involved in antibacterial action mechanisms: alkaloids isolated from Scutellariagenus. Asian J Pharm Clin Res 2016;9:121-5.

21. Manjula J, Maheswari R. Biological and docking studies of novel aroylhydrazones. Int J Pharm Pharm Sci 2017;9:81-5.

22. Sarath S, Anjali T. In silico design and molecular docking studies of some 1,2-benzisoxazole derivatives for their analgesic and anti-inflammatory activity. Int J Curr Pharm Res 2017;9:38-41.

\section{How to cite this article}

- $\quad$ Niraj Kumar jha, Pravir Kumar. Molecular docking studies for the comparative analysis of different biomolecules to target hypoxia-inducible factor-1A. Int J Appl Pharm 2017;9(4):83-89. 